\title{
Structuring the Interrelationships amongst the Progress Metrics behind Successful Implementation of Search Engine Optimization with respect to Developing Countries
}

\author{
Arnav Jain \\ Techture Structures Private \\ Limited \\ Indore, India
}

\author{
Remica Aggarwal \\ School of Business, University of \\ Petroleum \& Energy Studies, \\ Dehradun, India
}

\author{
Bhoomica Aggarwal \\ HCL Technologies Private Limited \\ Sector 126, Noida, India
}

\begin{abstract}
All the aspects of Digital Marketing, ranging from Search Engine Optimization (SEO), Social Media Marketing (SMM) to Pay-per Click (PPC) and even Search Engine Marketing (SEM) have served, and are still contributing towards the betterment of multiple businesses online. Present paper focuses on exploring various tools and techniques of SEO as well as various factors behind its successful implementation in Indian SMEs . It first explore the SEO in detail, its various tools and techniques, its benefits to Indian SMEs as well as various metrics for measuring the progress of SEO implementation and the level or extent of the success. Thereafter, it further study the interrelationship amongst the metrics using the application of Interpretive Structural Modeling (ISM) and MICMAC approach.
\end{abstract}

\section{Keywords}

Interpretive Structural Modeling (ISM), Search Engine Optimization, Digital marketing, Social media marketing

\section{INTRODUCTION}

The objective of every website owner is to top-list their website, when search engine results are being listed out. They are in a continuous need to maximize the number of users visiting their website. The best way to do this is via search engine optimization (SEO) technique. Search engine optimization (SEO) involves designing, writing, and coding a website in a way that helps to improve the volume and quality of traffic to your website from people using search engines. These "free," "organic," or "natural" rankings on the various search engines can be influenced, but not controlled, by effective SEO techniques. SEO may target different kinds of search, including image search, video search, academic search, news-search and industry-specific vertical search engines. SEO differs from local search engine optimization in that the latter is focused on optimizing a business' online presence so that its web pages will be displayed by search engines when a user enters a local search for its products or services. The majority of web traffic is driven by major search engines including Google, Bing, YouTube, AOL, Yahoo, Duck Duck Go, Ask Jeeves and other country-specific ones (e.g. Baidu in China).

Optimizing a website primarily involves editing its content and HTML and associated coding to both increase its relevance to specific keywords and to remove barriers to the indexing activities of search engines. Search engine optimizers may offer SEO as a stand-alone service or as a part of a broader marketing campaign[1]. Because effective SEO may require changes to the HTML source code of a site, SEO tactics may be incorporated into web site development and design. An experienced SEO company offers businesses logical solutions for exposure to the internet public through intense research and development to assure companies gain success within search engines. This primarily includes long term search engine placement; long term search engine popularity; highest website traffic \& conversion rate and dynamic search engine marketing techniques. The following section highlights some of the tactics and techniques of Search Engine Optimization[2].

(1) Increasing the website speed by optimizing the formats and responsive sizes of the uploaded media and eliminating loose links and pointless data that slows down loading time.

(2) Maintaining Mobile Friendliness over the website using the Mobile-Friendly Test tool by Google.

(3) Using Long Tail Keywords in Your SEO Strategy for a higher conversion rate. It is usually advisable for a just started SEO campaign .

(4) Producing In-Depth High-Quality Content and post articles online

(5) Updating and Republishing Old Blog Posts for getting better response from audience

(6) Increase the number of backlinks, their quality and the relevance between the original content and backlink

(7) Adding conversational phrases should be added while optimizing conversational voice search. Apply a keyword strategy that goes well with how people talk and ask questions in real-life situations.

(8) Switching the Website to https for securing the connection with the user and protecting their details. This also helps while doing online transactions and filling of e-commerce forms.

(9) Making a strong presence on social media. This gets appended by sharing useful content on the social channels to grow the follower base .

(10) Keyword search : finding the words and phrases that your customers use rather than industry jargon. 
(11) SEO Local : optimize your website to acquire foot traffic or local area interest . ask users for citations and reviews that will link back to you.

(12) Social SEO : use social cues such as twitter shares, facebook likes, and social bookmarking that heavily search rankings.

(13) Guest SEO : be a guest blogger on other related blogs .

(14) Having a short title tag [ 6 to 7 words at most ] with the most important keywords near the beginning and used only once ; avoiding cumbersome URL; creating user friendly URL for easy accessibility by viewers and search engines.

\section{METRICS FOR MEASURING THE PROGRESS OF SEO : SEO Metrics $[3,4,5]$}

1. Backlinks or referring domains (BL/RD): Along with quality and relevant content, backlinks are the most important ranking factor in SEO. The total number of backlinks matters. Secondly, relevancy and quality of the sites linking to you matters. The diversity of the referring (linking) domains matters. 10,000 backlinks from 500 websites is typically better than 2000 backlinks from 2 websites. Ahrefs to be one of the best tools for tracking backlinks and referring domains.

2. Bounces / bounce rate (BR) : When a user navigates to your website and immediately leaves, this is called a "bounce." A high bounce rate can nullify the amount of organic traffic you've worked so hard to acquire. This can tarnish your digital reputation and hurt sales. A high bounce rate indicates that your site is not meeting user expectations for some reason. It should be analyzed with your organic traffic metric (discussed below). Solutions to high bounce rates include boosting page loading speeds, improving a website's design for user experience, or changing your site content.

3. Traffic reports / organic traffic (TR/OT): Precisely this means the number of visitors, new and returning. The organic traffic metric gives you a quick glance at the immediate payoff of your SEO campaign. It's best to analyze organic traffic in its full scope due to the nature of SEO's evolution. Keyword popularity and search engine algorithms change daily. Identify how organic traffic changes on a week-byweek basis. A month-by-month overview can also give you a sense of how an SEO campaign dips and rises over time.

4. Entrance keywords (EK): What words are people using to find your site? What pages are they landing on ? There are plenty of great tools out there that will help you conduct keyword research, and then track your site's rankings for them over time. You can also look at Google Search Console to see the keywords that are driving traffic to your website.

5. Google page rank (GPR): This measurement is by google search engine to see how important those sites linking to yours are in relation to your site.

6. Time Spent on Site(TSS) : Analysing how much time organic traffic visitors actually spend on your site can indicate how effective your keyword selection has been. This metric should be analysed with bounce rate and organic traffic data. In general, the longer amount of time that visitors spend on your site, the more relevant its content. Furthermore, extended stays are high indicators of solid keyword crafting.
7. Page Authority (PA): A website's page authority (PA) indicates its capacity to achieve high organic traffic. Sites with higher PA are more likely to achieve higher Google rankings. Effective link-building on the site is the primary motivator for website page authority. A low PA (less than 25 ) indicates that it is a good indicator that you need to hone your SEO efforts in partnership with effective link-building strategies.

8. Domain Authority (DA): In tandem with page authority, spend some time monitoring your domain authority (DA). Your DA indicates your website's general authority, in comparison to the authority of other websites. The maximum DA score you can achieve is 100 . The higher the website DA, the greater the odds are at ranking highly for all content. Welloptimized, relevant content can enable a higher amount of authoritative backlinks, which can boost your DA.

9. Average Page Load Time (APLT): This is a key metric. If your site takes over three seconds to load, it may be contributing to your high bounce rate. By improving your load time by one second, businesses can earn $27 \%$ more conversions. Discussing solutions with the web host ; considering upgrading a hosting plan or changing image and multimedia files can also assist with loading time.

10. Keyword Rankings(KR): Regular insight into your keyword rankings can ensure that you are consistently choosing high-performing words. Inspect your keyword rankings in Google Search Console by navigating to the Search Analytics tab. From here, you can learn more about queries and clicks. Keyword popularity wanes with consumer whims-and Google's algorithms. For this reason, KPI can be a great indicator of the type of keyword likely to perform well, given your content and industry.

11. Conversion Tracking (CT): Conversion tracking can take a variety of forms, depending upon the nature of conversion that you are seeking. Non-commerce sites will classify conversions very differently than commerce-driven ones. KPI (keyword performance), bounce rates, and organic traffic numbers are all likely to influence conversion rates, for example. Comparing these numbers with your sales data is likely to give you greater insight into how your SEO efforts are paying off.

12. Organic Click Through Rate (OCTR): Your CTR refers to the number of clicks your content earns versus its Google impression. In general, the percentage is calculated by dividing clicks by the total impressions. A high CTR indicates that your site is earning a click almost as much as it is appearing in search listings. This can give Google a sense of your credibility as a site and accordingly boost rankings. A low CTR can indicate a variety of things. Low CTRs may point to poor ad or snippet crafting. It can also suggest inadequate keyword selection.

13. Pages Per Session/ Page views(PPS/PV) : Web pages that attract the most visitors. You will also see the web pages that are not performing for you. This metric gives marketers an opportunity to assess user engagement with site content. Much like bounce rates and time spent on your site, the pages per session metric presents a window into your users' minds and intuitions. In general, the more pages users are visiting per session, the greater the relevance of your content. It may also indicate a high-performing internal linking system.

14. Leads or sales (L/S): Typically lead generation sites will push visitors to fill out some kind of form that includes the 
person's name, phone number, and email address. The business then uses that contact information to qualify the lead and see if they are a good fit for the product/service. To track leads, you'll need to measure form completions. If the completion of the form on your site takes the visitor to a unique landing page, like a 'thank you' page, you can just setup a Destination goal in Google Analytics to see how many people reach that page. To track sales on your online website, you should set up Ecommerce tracking in Google Analytics. There are two types of tracking available: standard Ecommerce tracking, and enhanced Ecommerce tracking. While standard Ecommerce reports in Google Analytics allows you to analyse purchase activity on your site or app. You can see product and transaction information, average order value, Ecommerce conversion rate, time to purchase, and other data; Enhanced Ecommerce adds functionality by allowing you to see when customers have added items to their shopping carts, when they have started the checkout process, and when they have completed a purchase.

\section{ISM METHODOLOGY}

The modelling technique ISM was proposed by Warfield [6] . This technique stresses on creating a structured graph out of the set of unique interrelated variables. The technique works with the steps viz. First, identifying the relevant elements and establishing a contextual relationship amongst them . Next , an SSIM is developed to establish the led to relationship amongst the two variables $i \& j$. Thereafter, an initial reachability matrix and then a final reachability matrix is created which eventually lead to the development of the reachability set and antecedent set for each criterion. In every iteration a top level element is selected for which the reachability set and intersection sets are the same. Variables are further classified during the MICMAC analysis based on relative driving power and dependence power in to the categories like autonomous, dependent, driver and linkage.

\section{DEVELOPMENT OF ISM MODEL}

In this section, ISM model is developed for various metrics for measuring the progress of SEO implementation and the level or extent of the success. Some fourteen factors are considered viz. High or higher number of backlinks or referring domains (HBL/HRD), Low bounces/ Low bounce rate $(\mathrm{LB} / \mathrm{LBR})$, High traffic reports / high organic traffic (HTR/HOT), Better Entrance keywords (BEK) , Better Google page rank (BGPR), More Time Spent on Site(MTSS) Better Page Authority (BPA) , Better Domain Authority (BDA), lower Average Page Load Time (LAPLT), High Keyword Rankings(HKR), Conversion Tracking (CT)/ More conversions, High Organic Click Through Rate (HOCTR), High number of Pages Per Session/ Page views (HPPS/HPV), Better Leads or Better sales (BL/BS) .

\subsection{Construction of Structural Self - Interaction Matrix (SSIM)}

This matrix gives the pair-wise relationship between two variables i.e. $i$ and $j$ based on VAXO. SSIM has been presented below in Fig 1 .

\subsection{Construction of Initial Reachability Matrix and final reachability matrix}

The SSIM has been converted in to a binary matrix called the initial reachability matrix shown in fig. 2 by substituting V, A, $\mathrm{X}, \mathrm{O}$ by 1 or 0 as per the case. After incorporating the transitivity, the final reachability matrix is shown below in the Fig 3.

Fig 1: SSIM matrix for pair wise relationship amongst barriers

\begin{tabular}{|c|c|c|c|c|c|c|c|c|c|c|c|c|c|c|c|}
\hline S.N & Barriers & 1 & 2 & 3 & 4 & 5 & 6 & 7 & 8 & 9 & 10 & 11 & 12 & 13 & 14 \\
\hline & & $\begin{array}{c}\mathrm{HBL} \\
/ \mathrm{HR} \\
\mathrm{D}\end{array}$ & $\begin{array}{l}\mathrm{LB} / \\
\mathrm{LBR}\end{array}$ & $\begin{array}{c}\text { HTR } \\
/ \text { /HO } \\
\text { T }\end{array}$ & BEK & $\begin{array}{c}\text { BGP } \\
\text { R }\end{array}$ & $\begin{array}{c}\text { MTS } \\
\text { S }\end{array}$ & BPA & BDA & $\begin{array}{l}\text { LAP } \\
\text { LT }\end{array}$ & HKR & CT & $\begin{array}{c}\text { HOC } \\
\text { TR }\end{array}$ & $\begin{array}{c}\text { HPPS/ } \\
\text { HPV }\end{array}$ & $\mathrm{BL} / \mathrm{BS}$ \\
\hline 1 & $\begin{array}{c}\mathrm{HBL} / \mathrm{H} \\
\mathrm{RD}\end{array}$ & & $\mathrm{X}$ & V & A & V & V & V & V & V & A & V & $X$ & $\mathrm{X}$ & $\mathrm{X}$ \\
\hline 2 & LB/LBR & & & $X$ & A & $\mathrm{V}$ & A & $\mathrm{X}$ & $X$ & $\mathrm{X}$ & A & $\mathrm{V}$ & $\mathrm{X}$ & $X$ & $\mathrm{X}$ \\
\hline 3 & $\begin{array}{c}\text { HTR/H } \\
\text { OT }\end{array}$ & & & & A & V & $X$ & V & V & V & $X$ & V & $X$ & V & V \\
\hline 4 & BEK & & & & & $\mathrm{V}$ & $\mathrm{V}$ & $\mathrm{V}$ & $\mathrm{V}$ & $\mathrm{V}$ & $X$ & $\mathrm{~V}$ & $\mathrm{~V}$ & $\mathrm{~V}$ & $\mathrm{~V}$ \\
\hline 5 & BGPR & & & & & & $\mathrm{X}$ & $\mathrm{X}$ & $X$ & $\mathrm{~V}$ & A & $\mathrm{O}$ & A & A & A \\
\hline 6 & MTSS & & & & & & & $\mathrm{X}$ & $X$ & $\mathrm{~V}$ & A & $\mathrm{V}$ & $\mathrm{V}$ & $X$ & $\mathrm{~V}$ \\
\hline 7 & BPA & & & & & & & & $\mathrm{V}$ & $\mathrm{V}$ & A & $\mathrm{V}$ & $\mathrm{V}$ & A & $\mathrm{A}$ \\
\hline 8 & BDA & & & & & & & & & $\mathrm{V}$ & A & $\mathrm{V}$ & $\mathrm{V}$ & A & A \\
\hline 9 & LAPLT & & & & & & & & & & $\mathrm{O}$ & $\mathrm{O}$ & $\mathrm{O}$ & $\mathrm{O}$ & $\mathrm{O}$ \\
\hline 10 & HKR & & & & & & & & & & & $\mathrm{V}$ & $\mathrm{V}$ & $\mathrm{V}$ & $\mathrm{V}$ \\
\hline 11 & CT & & & & & & & & & & & & A & A & V \\
\hline 12 & HOCTR & & & & & & & & & & & & & $\mathrm{V}$ & $\mathrm{V}$ \\
\hline 13 & $\begin{array}{c}\text { HPPS/H } \\
\text { PV }\end{array}$ & & & & & & & & & & & & & & $\mathrm{V}$ \\
\hline 14 & BL/BS & & & & & & & & & & & & & & \\
\hline
\end{tabular}


Fig 2: Initial reachability matrix

\begin{tabular}{|c|c|c|c|c|c|c|c|c|c|c|c|c|c|c|c|}
\hline S. & Barriers & 1 & 2 & 3 & 4 & 5 & 6 & 7 & 8 & 9 & 10 & 11 & 12 & 13 & 14 \\
\hline & & $\begin{array}{c}\mathrm{HBL} / \mathrm{H} \\
\mathrm{RD}\end{array}$ & $\begin{array}{c}\mathrm{LB} / \mathrm{L} \\
\mathrm{BR}\end{array}$ & $\begin{array}{l}\text { HTR/ } \\
\text { HOT }\end{array}$ & BEK & BGPR & $\begin{array}{c}\text { MTS } \\
\text { S }\end{array}$ & BPA & BDA & $\begin{array}{c}\text { LAP } \\
\text { LT }\end{array}$ & HKR & CT & $\begin{array}{c}\text { HOCT } \\
\text { R }\end{array}$ & $\begin{array}{c}\text { HPPS/ } \\
\text { HPV }\end{array}$ & $\mathrm{BL} / \mathrm{BS}$ \\
\hline 1 & $\begin{array}{c}\mathrm{HBL} / \mathrm{HR} \\
\mathrm{D}\end{array}$ & 1 & 1 & 1 & 0 & 1 & 1 & 1 & 1 & 1 & 0 & 1 & 1 & 1 & 1 \\
\hline 2 & LB/LBR & 1 & 1 & 1 & 0 & 1 & 0 & 1 & 1 & 1 & 0 & 1 & 1 & 1 & 1 \\
\hline 3 & $\begin{array}{c}\mathrm{HTR} / \mathrm{HO} \\
\mathrm{T}\end{array}$ & 0 & 1 & 1 & 0 & 1 & 1 & 1 & 1 & 1 & 1 & 1 & 1 & 1 & 1 \\
\hline 4 & BEK & 1 & 1 & 1 & 1 & 1 & 1 & 1 & 1 & 1 & 1 & 1 & 1 & 1 & 1 \\
\hline 5 & BGPR & 0 & 0 & 0 & 0 & 1 & 1 & 1 & 1 & 1 & 0 & 0 & 0 & 0 & 0 \\
\hline 6 & MTSS & 0 & 1 & 1 & 0 & 1 & 1 & 1 & 1 & 1 & 0 & 1 & 1 & 1 & 1 \\
\hline 7 & $\mathrm{BPA}$ & 0 & 1 & 0 & 0 & 1 & 1 & 1 & 1 & 1 & 0 & 1 & 1 & 0 & 0 \\
\hline 8 & BDA & 0 & 1 & 0 & 0 & 1 & 1 & 0 & 1 & 1 & 0 & 1 & 1 & 0 & 0 \\
\hline 9 & LAPLT & 0 & 1 & 0 & 0 & 0 & 0 & 0 & 0 & 1 & 0 & 0 & 0 & 0 & 0 \\
\hline 10 & HKR & 1 & 1 & 1 & 0 & 1 & 1 & 1 & 1 & 1 & 1 & 1 & 1 & 1 & 1 \\
\hline 11 & CT & 0 & 0 & 0 & 0 & 0 & 0 & 0 & 0 & 1 & 0 & 1 & 0 & 0 & 1 \\
\hline 12 & HOCTR & 1 & 1 & 1 & 0 & 1 & 0 & 0 & 0 & 1 & 0 & 1 & 1 & 1 & 1 \\
\hline 13 & $\begin{array}{c}\text { HPPS/HP } \\
\mathrm{V}\end{array}$ & 1 & 1 & 0 & 0 & 1 & 1 & 1 & 1 & 1 & 0 & 1 & 0 & 1 & 1 \\
\hline 14 & BL/BS & 1 & 1 & 0 & 0 & 1 & 0 & 1 & 1 & 1 & 0 & 0 & 0 & 0 & 1 \\
\hline
\end{tabular}

Fig 3: Final reachability matrix

\begin{tabular}{|c|c|c|c|c|c|c|c|c|c|c|c|c|c|c|c|c|}
\hline S.No & Barriers & 1 & 2 & 3 & 4 & 5 & 6 & 7 & 8 & 9 & 10 & 11 & 12 & 13 & 14 & \\
\hline & & $\begin{array}{c}\mathrm{HBL} \\
/ \mathrm{HR} \\
\mathrm{D}\end{array}$ & $\begin{array}{c}\mathrm{LB} / \mathrm{L} \\
\mathrm{BR}\end{array}$ & $\begin{array}{c}\mathrm{HTR} \\
/ \mathrm{HO} \\
\mathrm{T}\end{array}$ & BEK & BGPR & $\begin{array}{c}\text { MTS } \\
\text { S }\end{array}$ & BPA & BDA & $\begin{array}{c}\text { LAP } \\
\text { LT }\end{array}$ & HKR & CT & $\begin{array}{c}\text { HOCT } \\
\text { R }\end{array}$ & $\begin{array}{c}\text { HPPS/ } \\
\text { HPV }\end{array}$ & $\mathrm{BL} / \mathrm{BS}$ & \\
\hline 1 & $\begin{array}{c}\text { HBL/HR } \\
\text { D }\end{array}$ & 1 & 1 & 1 & 0 & 1 & 1 & 1 & 1 & 1 & 1 & 1 & 1 & 1 & 1 & 13 \\
\hline 2 & LB/LBR & 1 & 1 & 1 & 0 & 1 & 1 & 1 & 1 & 1 & 1 & 1 & 1 & 1 & 1 & 13 \\
\hline 3 & $\begin{array}{c}\mathrm{HTR} / \mathrm{HO} \\
\mathrm{T}\end{array}$ & 0 & 1 & 1 & 0 & 1 & 1 & 1 & 1 & 1 & 1 & 1 & 1 & 1 & 1 & 12 \\
\hline 4 & BEK & 1 & 1 & 1 & 1 & 1 & 1 & 1 & 1 & 1 & 1 & 1 & 1 & 1 & 1 & 14 \\
\hline 5 & BGPR & 0 & 1 & 1 & 0 & 1 & 1 & 1 & 1 & 1 & 0 & 1 & 1 & 1 & 1 & 11 \\
\hline 6 & MTSS & 0 & 1 & 1 & 0 & 1 & 1 & 1 & 1 & 1 & 1 & 1 & 1 & 1 & 1 & 12 \\
\hline 7 & BPA & 0 & 1 & 1 & 0 & 1 & 1 & 1 & 1 & 1 & 0 & 1 & 1 & 1 & 1 & 11 \\
\hline 8 & BDA & 0 & 1 & 0 & 0 & 1 & 1 & 1 & 1 & 1 & 0 & 1 & 1 & 1 & 1 & 10 \\
\hline 9 & LAPLT & 1 & 1 & 1 & 0 & 1 & 1 & 1 & 1 & 1 & 1 & 1 & 1 & 1 & 1 & 13 \\
\hline 10 & HKR & 1 & 1 & 1 & 0 & 1 & 1 & 1 & 1 & 1 & 1 & 1 & 1 & 1 & 1 & 13 \\
\hline 11 & CT & 1 & 1 & 1 & 0 & 1 & 1 & 1 & 1 & 1 & 0 & 1 & 1 & 1 & 1 & 12 \\
\hline 12 & HOCTR & 1 & 1 & 1 & 0 & 1 & 1 & 1 & 1 & 1 & 0 & 1 & 1 & 1 & 1 & 12 \\
\hline 13 & $\begin{array}{c}\text { HPPS/HP } \\
\mathrm{V}\end{array}$ & 1 & 1 & 1 & 0 & 1 & 1 & 1 & 1 & 1 & 1 & 1 & 1 & 1 & 1 & 13 \\
\hline \multirow[t]{2}{*}{14} & $\mathrm{BL} / \mathrm{BS}$ & 1 & 1 & 1 & 0 & 1 & 1 & 1 & 1 & 1 & 0 & 1 & 1 & 1 & 1 & 12 \\
\hline & De. P & 9 & 14 & 13 & 1 & 14 & 14 & 14 & 14 & 14 & 8 & 14 & 14 & 14 & 14 & \\
\hline
\end{tabular}




\subsection{Level Partition}

level element, it is separated out from the other elements and the process continues for next level of elements. Iterations have been shown from table 4 - table 7 below .

\section{Table 4 : Iteration II}

\begin{tabular}{|c|c|c|c|c|}
\hline $\begin{array}{l}\text { Sr. } \\
\text { No. }\end{array}$ & $\begin{array}{c}\text { Reachability } \\
\text { set }\end{array}$ & $\begin{array}{l}\text { Antecedent } \\
\text { set }\end{array}$ & $\begin{array}{c}\text { Intersection } \\
\text { set }\end{array}$ & $\begin{array}{l}\text { Itera } \\
\text { tion }\end{array}$ \\
\hline 1. & $\begin{array}{l}2,5,6,7,8,9 \\
11,12,13,14\end{array}$ & $\begin{array}{c}1,2,3,4,5,6 \\
7,8,9,10,11, \\
12,13,14\end{array}$ & $\begin{array}{c}2,5,6,7,8,9,11 \\
, 12,13,14\end{array}$ & \\
\hline 2. & $\begin{array}{c}2,3,5 \\
6,7,8,9 \\
11,12,13,14\end{array}$ & $\begin{array}{c}1,2,3,4,5,6, \\
7,9,10,11,1 \\
2,13,14\end{array}$ & $\begin{array}{c}2,3,5,6,7,9,11 \\
, 12,13,14\end{array}$ & I \\
\hline 3. & $\begin{array}{c}1,2,3,5,6,7 \\
8,9 \\
11,12,13,14\end{array}$ & $\begin{array}{c}1,2,4,9,10,1 \\
1,12,13,14\end{array}$ & $\begin{array}{c}1,2,9,11,12,1 \\
3,14\end{array}$ & \\
\hline 4. & $\begin{array}{c}1,2,3,5,6 \\
7,8,9,10 \\
11,12,13,14\end{array}$ & $\begin{array}{c}1,2,4,9,10,1 \\
3,14\end{array}$ & $\begin{array}{c}1,2,9,10 \\
13,14\end{array}$ & \\
\hline 5. & $\begin{array}{l}1,2,3,4,5 \\
6,7,8,9,10 \\
11,12,13,14\end{array}$ & 4 & 4 & \\
\hline
\end{tabular}

Table 4 : Iteration II

\begin{tabular}{|c|c|c|c|c|}
\hline $\begin{array}{c}\text { Sr. } \\
\text { No. }\end{array}$ & $\begin{array}{c}\text { Reachability } \\
\text { set }\end{array}$ & $\begin{array}{c}\text { Antecedent } \\
\text { set }\end{array}$ & $\begin{array}{c}\text { Intersection } \\
\text { set }\end{array}$ & $\begin{array}{c}\text { Itera } \\
\text { tion }\end{array}$ \\
\hline 2. & $\mathbf{3}$ & $1,3,4,10$ & $\mathbf{3}$ & \\
\cline { 1 - 4 }. & 1,3 & $1,4,10$ & 1 & \multirow{2}{*}{ II } \\
\cline { 1 - 4 } & $1,3,10$ & $1,4,10$ & 1,10 & \\
\hline 5. & $1,3,4,10$ & 4 & 4 & \\
\hline
\end{tabular}

Table 5 : Iteration III

\begin{tabular}{|c|c|c|c|c|}
\hline $\begin{array}{c}\text { Sr. } \\
\text { No. }\end{array}$ & $\begin{array}{c}\text { Reachability } \\
\text { set }\end{array}$ & $\begin{array}{c}\text { Antecedent } \\
\text { set }\end{array}$ & $\begin{array}{c}\text { Intersection } \\
\text { set }\end{array}$ & $\begin{array}{c}\text { Itera } \\
\text { tion }\end{array}$ \\
\hline 3. & $\mathbf{1}$ & $1,4,10$ & $\mathbf{1}$ & \multirow{2}{*}{ III } \\
\cline { 1 - 4 } & 1,10 & $1,4,10$ & 1,10 & \\
\hline 5. & $1,4,10$ & 4 & 4 & \\
\hline
\end{tabular}

Table 6 : Iteration IV

\begin{tabular}{|c|c|c|c|c|}
\hline $\begin{array}{c}\text { Sr. } \\
\text { No. }\end{array}$ & $\begin{array}{c}\text { Reachability } \\
\text { set }\end{array}$ & $\begin{array}{c}\text { Antecedent } \\
\text { set }\end{array}$ & $\begin{array}{c}\text { Intersection } \\
\text { set }\end{array}$ & $\begin{array}{c}\text { Itera } \\
\text { tion }\end{array}$ \\
\hline 4. & $\mathbf{1 0}$ & 4,10 & $\mathbf{1 0}$ & \\
\cline { 1 - 4 } & 4,10 & 4 & 4 & IV \\
\hline
\end{tabular}

Table 7 : Iteration V

\begin{tabular}{|l|l|l|l|l|}
\hline $\begin{array}{l}\text { Sr. } \\
\text { No. }\end{array}$ & $\begin{array}{l}\text { Reachability } \\
\text { set }\end{array}$ & $\begin{array}{l}\text { Antecedent } \\
\text { set }\end{array}$ & $\begin{array}{l}\text { Intersection } \\
\text { set }\end{array}$ & $\begin{array}{l}\text { Itera } \\
\text { tion }\end{array}$ \\
\hline 5. & $\mathbf{4}$ & 4 & $\mathbf{4}$ & $\mathbf{V}$ \\
\hline
\end{tabular}

\subsection{Classification of factors}

Fig. 4 below shows the driving power and dominance diagram.

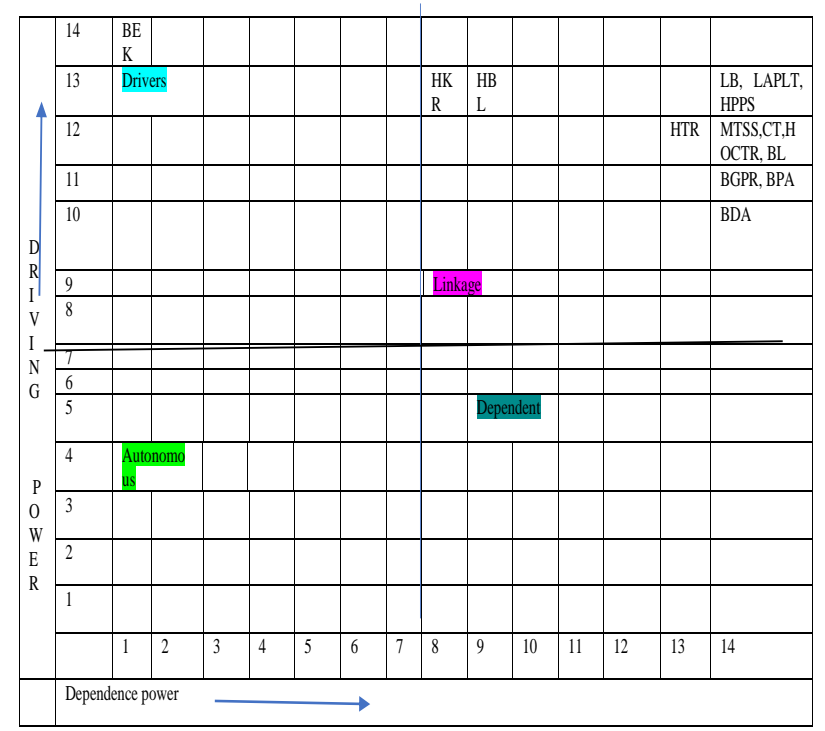

Fig . 4: Driving power and dependence diagram

\subsection{ISM model}

An ISM model is developed ( as shown in fig. 5 below ) after arranging the elements as per their interaction or dependence relationships.

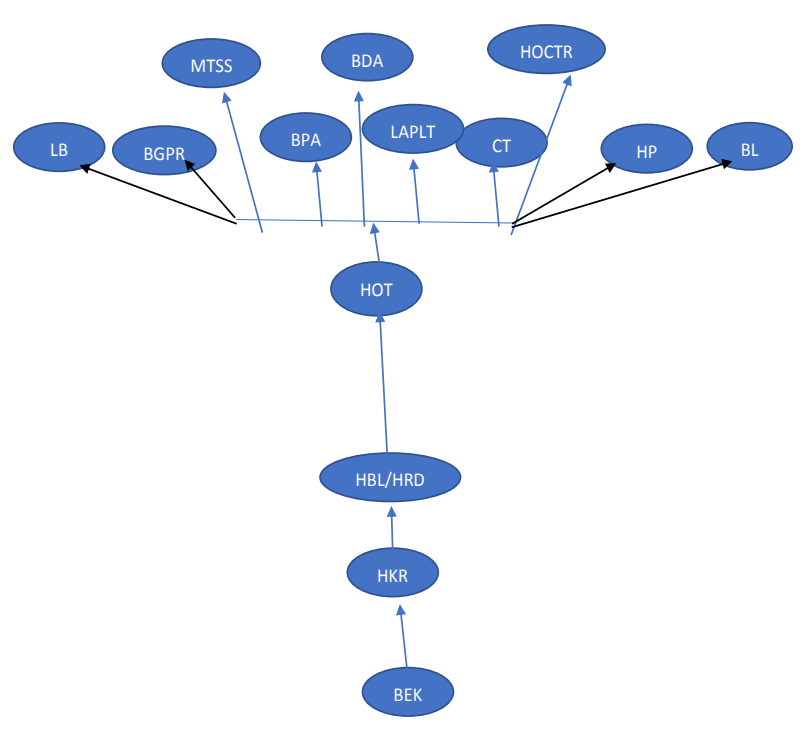




\section{MANAGERIAL IMPLICATIONS \& CONCLUSIONS}

- Personal SEO results. With users offering personal information to profiling sites like Facebook, Twitter, Google Places, etc. and search engines able to track personal preferences via user clicks, search results and advertisements can now be customized to suit individual preferences.

- Quality vs. quantity. With the introduction of Google Panda (one of Google's ranking search engine filters that aims to lower the rank of lowquality sites), review and clean up of your site must be ongoing to ensure your pages offer quality content, not just quantity. It is therefore important to maintain the quality of web content and also make sure that the posted content is relevant and fresh.

- Businesses can ask partners e.g. suppliers, other businesses, professional organisations, chambers of commerce and customers to add links from their website.

- When searching for a search engine optimisation expert it's important to find a company or individual with a proven track record in SEO. Making it to the top of a search engine results page requires the experience of an expert, who is knowledgeable and proven in his skills.

- Adaptation of internet for e-commerce: a potential marketing opportunity for SMEs: The widening of the exposure of SMEs would result in the increase of marketing channels as well as direct and indirect revenue streams [7]. Berman and McClellan (2002) note that inclusion of e-commerce into the business processes would result in enhanced profitability for the business.

- Monitoring SEO performance is central to driving results in any optimization campaign. When you generate SEO reports for any given campaign always take time to analyze the right metrics.

- In particular, prioritize the metrics that give insight into the value of your content. These include bounce rates, pages per session metrics, and time spent on site data. Scrutinize organic traffic totals as well as organic click-through rates.

\section{ACKNOWLEDGMENTS}

Our thanks to the anonymous reviewers whose comments have helped us in improving the manuscript . Co-author Remica Aggarwal is also thankful to Prof. S.P Singh in disseminating the knowledge about ISM methodology

\section{REFERENCES}

[1] Levene, M. 2010. An introduction to search engines and web navigation. Oxford: John Wiley \& Sons.

[2] Humayun, M. 2009. Optimizing websites for higher search engine ranking. Unpublished MSc dissertation. Sheffield: Sheffield University.

[3] https://www.wpromote.com/blog/top-seo-kpis

[4] https://blog.rankwatch.com/top-10-metrics-formonitoring-seo-performance-the-smart-way/ ]

[5] Malaga, A.R. 2007. The value of search engine optimization: an action research project at a new ecommerce site. Journal of Electronic Commerce in Organizations, 5(3), 918-929.

[6] Warfield, J., N. 1974. Developing interconnection matrices in structural modeling. In the proceedings of IEEE Transactions on System, Man, and Cybernetics (SMC), 4 (1), 81-87.

[7] Steenderen, V.M. 2001. Web site management: making a web site more visible. Available at: http://www.sajim.co.za 